\title{
A Construção Poética das Formas, uma aproximação entre artes e matemática através da computação gráfica
}

\section{La construcción poética de las formas, una aproximación entre las artes y las matemáticas por computadora}

Poetic construction of forms, an approach between arts and mathematics through computer graphics

\author{
Alessandro Alves Silva \\ Doutor em Física. USP, Instituto de Física \\ alessandro.alves.silva@usp.br \\ Priscilla Barranqueiros Ramos Nannini \\ Doutora em Artes. UNESP, Instituto de Artes \\ prnannini@uol.com.br
}

RESUMO

Atividade interdisciplinar entre Artes e Matemática, voltada para o Ensino Médio, com a proposta de trabalhar os conhecimentos da Arte Concreta Brasileira, relacionando os elementos geométricos usados por esses artistas com conceitos da matemática.

Palavras chave: Arte, Matemática, Design, Computação Gráfica, Arte Concreta

\section{RESUMEN}

Actividad interdisciplinaria entre Artes y Matemáticas, dirigida a la escuela secundaria, con la propuesta de trabajar el conocimiento del arte concreto brasileño, relacionando los elementos geométricos utilizados por estos artistas con los conceptos de las matemáticas.

Palabras clave: Arte, Matemáticas, Diseño, Computación Grafica, Arte Concreto

\section{ABSTRACT}

Interdisciplinary activity between Arts and Mathematics aimed at high school with the proposal to work with Brazilian Concrete Art, relating geometric elements used by these artists with concepts of mathematics.

Keywords: Art, Mathematics, Design, CG, Concrete art 


\section{Introdução}

O estudo de geometria nas escolas é focado, principalmente, na aplicação e memorização de fórmulas e conceitos, mas, se estas forem às únicas estratégias de ensino, sem levar em consideração abordagens da história, bem como suas aplicações em ciências, arquitetura, engenharia, etc., há o risco de desenvolver nos alunos resistência de aprendizado, culminando em processos avaliativos decepcionantes e meramente classificatórios.

Diante desse quadro, foi elaborado um projeto conjunto entre as disciplinas de Artes e Matemática, tendo por objetivo o estudo de importantes movimentos artísticos que utilizaram a geometria como uma linguagem para a composição de suas obras, dando origem a um projeto interdisciplinar, que deu origem ao curso extracurricular $A$ Construção Poética das Formas.

Por ser um curso extracurricular, não há preferências sobre a série de origem do aluno (desde que seja do Ensino Médio), ou seja, é um curso aberto a quem quiser fazer e o foco é estabelecer relações entre a Arte Concreta, a Geometria e a junção dessas duas áreas por meio da elaboração de projetos de investigação feito pelos alunos através de desenhos, croquis, esquemas, com o uso do Desenho Assistido por Computador (CAD), no caso, o FreeCAD, que é um software livre e gratuito, equivalente ao AutoCAD da AutoDesk (software proprietário e pago).

O projeto, desenvolvido e oferecido a alunos do ensino médio, foi pensado nas seguintes frentes:

a) Apresentação e análise de figuras geométricas planas e tridimensionais e de fácil compreensão, tais como quadriláteros, triângulos, círculos, etc. A discussão desses elementos geométricos foi feito de forma rápida, sem uma preocupação com o rigor das definições.

b) Desenvolvimento e discussão dos principais movimentos artísticos, nacionais e internacionais, que tiveram como base de elaboração a geometria na criação de suas obras, que culminaram significativamente no surgimento da arte abstrata geométrica. No Brasil temos como representante o Grupo Ruptura (SP), composto por artistas como Waldemar Cordeiro, Geraldo de Barros, Luis Sacilotto, Lothar Charoux, e o Grupo Frente (RJ), fundado por Ferreira Gullar, Lygia Clark, Lygia Pape, Ivan Serpa, entre outros. No âmbito internacional, temos as experiências do Construtivismo Russo e da Bauhaus, movimentos que influenciaram tanto a arte, como a arquitetura e o design, e que tiveram o estudo da geometria abstrata como uma das chaves de criação.

c) Utilização do programa de construção gráfica FreeCad, em que os alunos fizeram diversas investigações a partir das ferramentas de construção e manipulação geométricas disponíveis.
O projeto foi aplicado em dois semestres sendo que no 1 으 os alunos trabalharam na elaboração de estruturas e desenhos

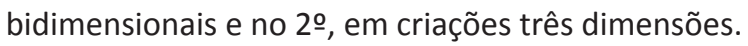

\section{Arte concreta e matemática}

O artista Theo van Doesburg (1883-1931) é quem usa o termo arte concreta, mesmo nome usado pelo grupo e na revista, fundados em 1930, em Paris. No texto de introdução do 1 o número da revista Arte Concreta, conceitua o que seria a base da pintura concreta ${ }^{3}$ :

1ㅇ A arte é universal; 20 A obra de arte deve ser inteiramente concebida e formada pelo espírito antes de sua execução [...]; 3o O quadro deve ser inteiramente construído com elementos puramente plásticos, isto é, planos e cores. Um elemento pictural só significa a 'si próprio' e, consequentemente o quadro não tem outra significação que 'ele mesmo'; 4ㅇ A construção do quadro, assim como seus elementos, deve ser simples e controlável visualmente; 5ㅇ A técnica deve ser mecânica, isto é, exata, antiimpressionista; 6ㅇ Esforço pela clareza absoluta.

A arte concreta se afasta inteiramente da representação da natureza; negando as correntes artísticas subjetivistas e líricas. Com base na interpretação destes "postulados", percebemos que esta arte possui finalidade em si mesma, sem uma preocupação em metaforizar sentimentos, situações políticas ou sociais.

A matemática torna-se a linguagem da arte concreta, principalmente com o uso de sólidos e figuras geométricas, e tal afirmação pode ser confirmada a seguir ${ }^{4}$ :

A arte concreta é herdeira das pesquisas do grupo De Stijl [O Estilo], de Piet Mondrian e Van Doesburg, que busca a pureza e o rigor formal na ordem harmônica do universo. Além disso, parte de ideais da Bauhaus, nos quais a racionalidade deve estar presente em todos os âmbitos sociais e nas conquistas da arte democratizadas pela indústria. O artista Max Bill (1908-1994), nos anos 1950, com a Escola Superior da Forma, tenta levar adiante esse projeto. Para Bill, um dos principais responsáveis pela divulgação da arte concreta na América Latina, a matemática é o meio mais eficiente para o conhecimento da realidade objetiva e uma obra plástica deve ser ordenada pela geometria e pela clareza da forma.

\section{Metodologia de trabalho}

A execução do projeto foi dividida em duas etapas:

3 e 4 Arte Concreta. Disponível em: <http://enciclopedia.itaucultural.org. br/termo3777/arte-concreta>. Acesso em 10 jan. 2020. 
1. Apresentação e treinamento do programa gráfico FreeCad (figura 1): nesta fase os alunos recebem instruções e comandos básicos para a construção de figuras planas (quadriláteros, triângulos, etc.) e sólidos geométricos mais gerais (cubos, esferas, etc.). A partir destas estruturas mais simples e dos comandos de manipulação que permitem a junção, recorte, preenchimento, alterações de escalas e posições, os alunos devem realizar composições para a formação de novas estruturas.

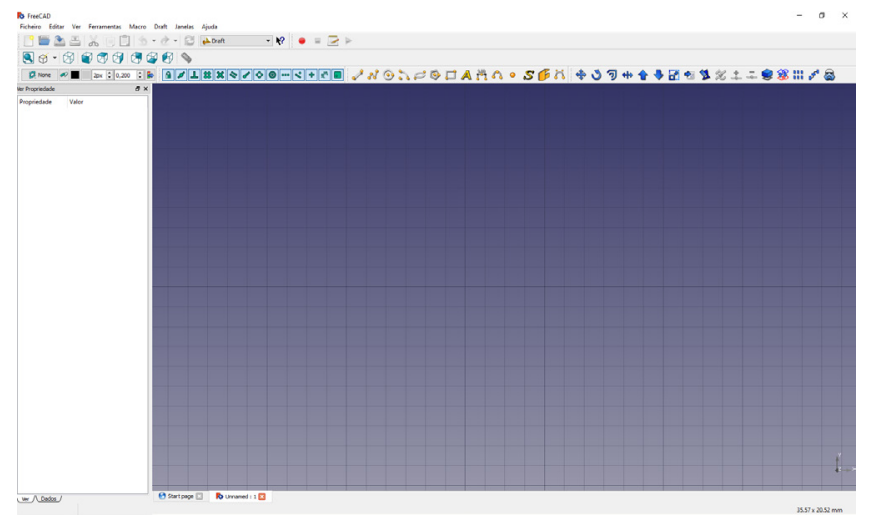

Figura 1: Tela do programa: uso do plano cartesiano para construção dos objetos geométricos. Foto: Alessandro Alves

2. Após o período de treinamento foi solicitado a eles uma pesquisa para a escolha de um artista representante da Arte Concreta, que deveria servir de inspiração para a criação de uma arte. Nesta fase, os alunos fazem um croqui do projeto à mão e, então, retornam aos computadores para a confecção eletrônica do projeto, podendo assim, visualizar o produto final antes da materialização.

\section{Resultados e análise}

A seguir são apresentados alguns exemplos dos trabalhos dos alunos. Nas figuras 3 e 4 temos um projeto desenvolvido a partir do estudo das obras de Hércules Barsotti (1914-2010), artista que sempre pesquisou as diferentes configurações do espaço, usando com rigor as possibilidades da cor e da forma (figura 2). O aluno busca mesclar geometria e cores inspirado nas leituras do artista escolhido, chegando a um resultado satisfatório com uma criação autônoma.

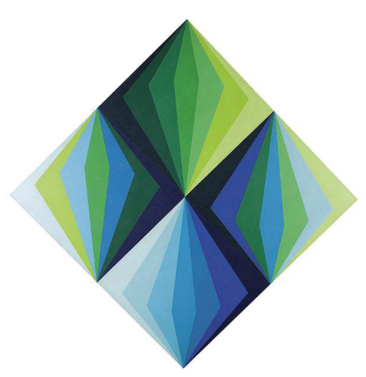

Figura 2: Hércules Barsotti, Opostos Determinantes, s/data. Fonte: https://vejasp.abril.com.br/wp-content/uploads/2016/11/4215jpg.jpeg?quality $=70 \&$ strip=info\& $w=603$

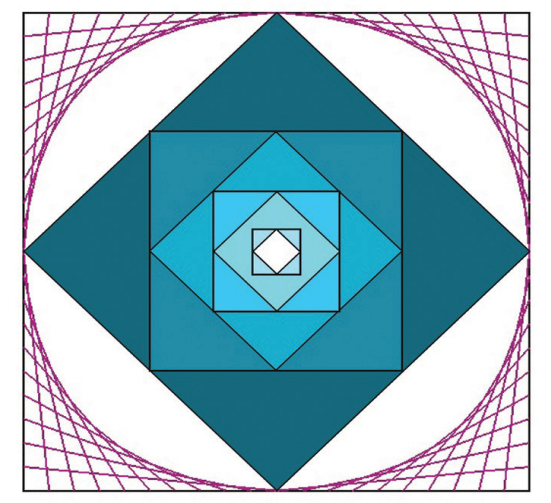

Figura 3 (acima): Projeto feito no computador. Foto: Priscilla Nannini

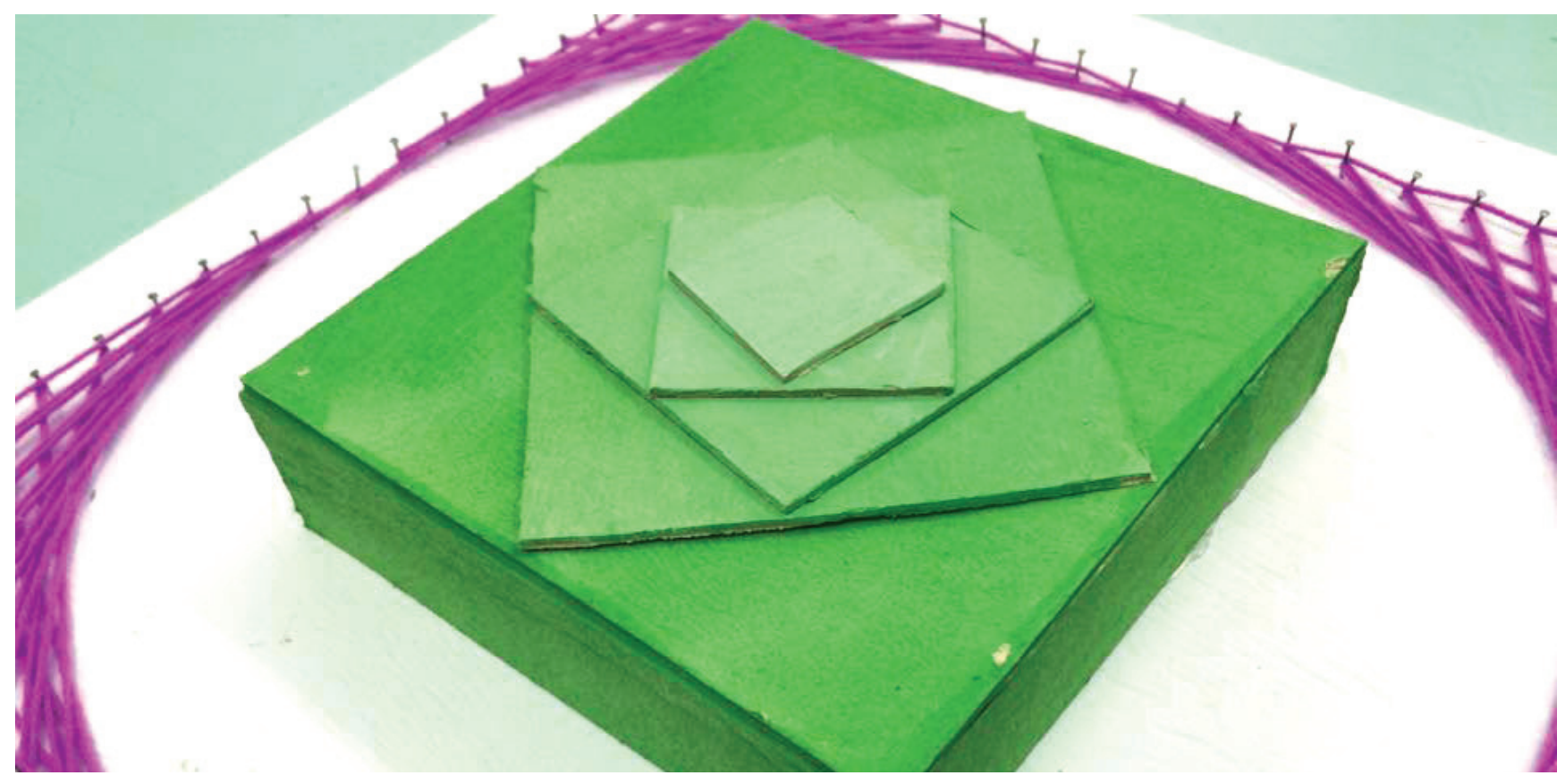


As figuras 5 e 6 são criações pensadas a partir de Geraldo de Barros (1923-1998) e Luiz Sacilotto (1924-2003), que aliavam ao rigor matemático de suas obras uma alta dosagem experimental, além de Alfredo Volpi (1896-1988), não propriamente um artista construtivo, mas cuja obra dialoga com esta vertente. A repetição da forma, o uso de tons de azuis presentes em Volpi e a marcante geometria do concretismo seguem como inspiração nessa pesquisa visual.

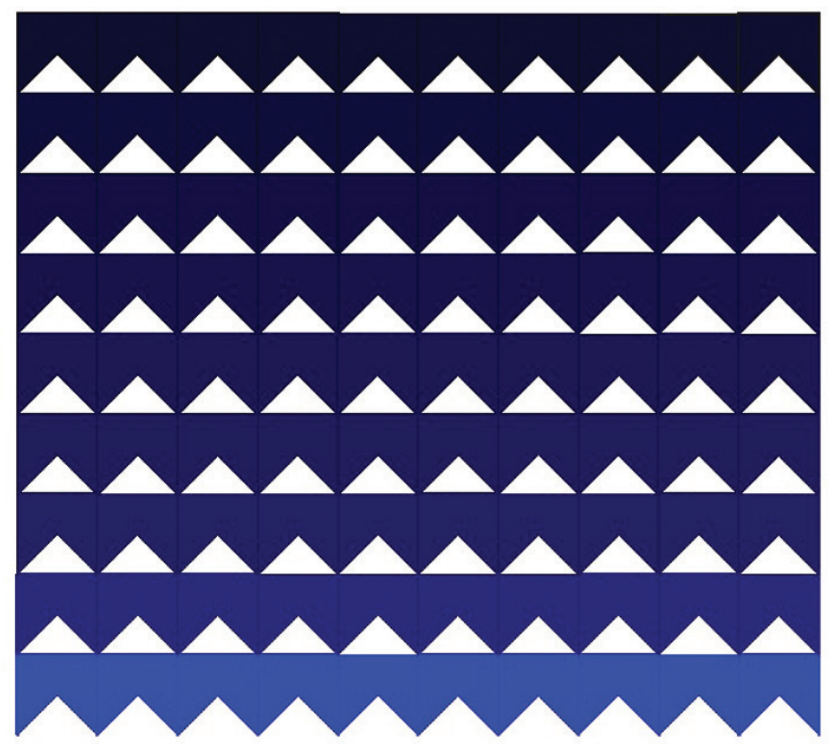

Figura 5: Projeto feito no computador. Foto: Priscilla Nannini

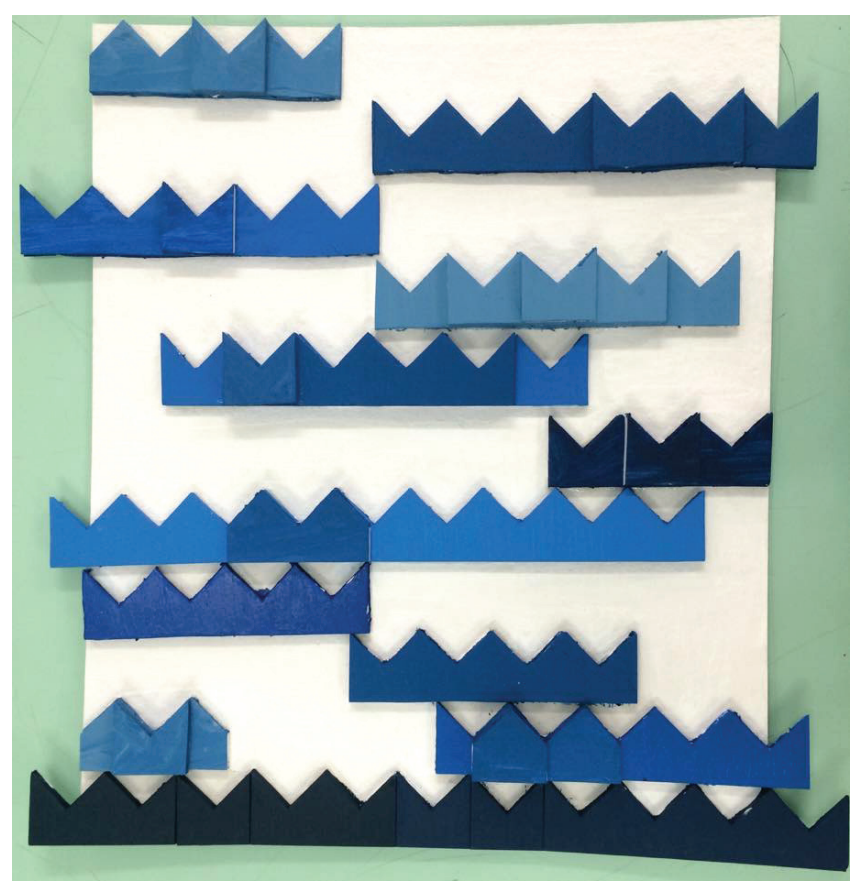

Figura 6: Arte final inspirada em Volpi, Geraldo de Barros e Sacilotto. Foto: Prisiclla Nannini

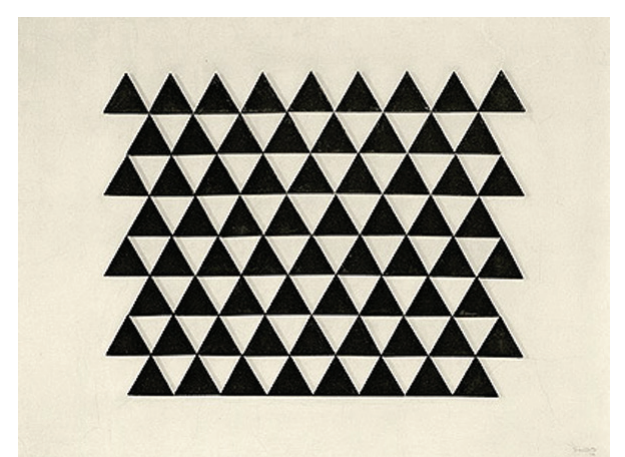

Figura 7: Luiz Sacilotto, Concretion, 1956. Fonte: https://d3swacfcujrr1g.cloudfront.net/ img/uploads /2000/01/009272001019.jpg

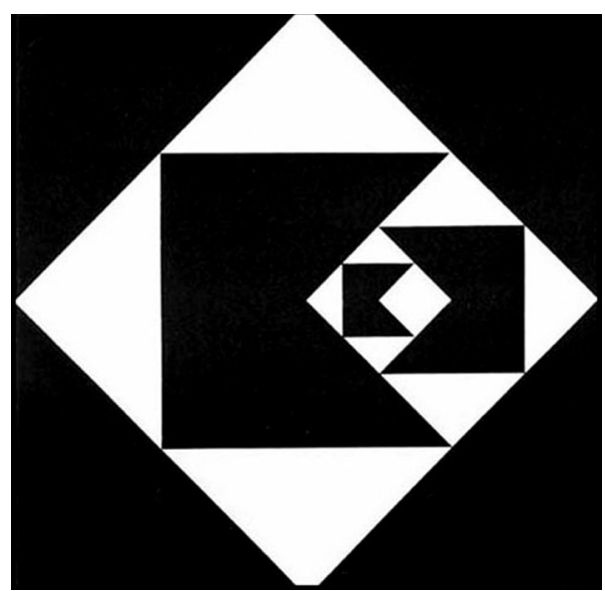

Figura 8: Geraldo de Barros, Objeto-forma 1979. Fonte: https://comunicacaoeartes20122. files. wordpress.com $/ 2013 / 01 /$ geraldode-barros-1923-98-objeto-forma-esmalte1979-080x080-col-part.jpg?w=500

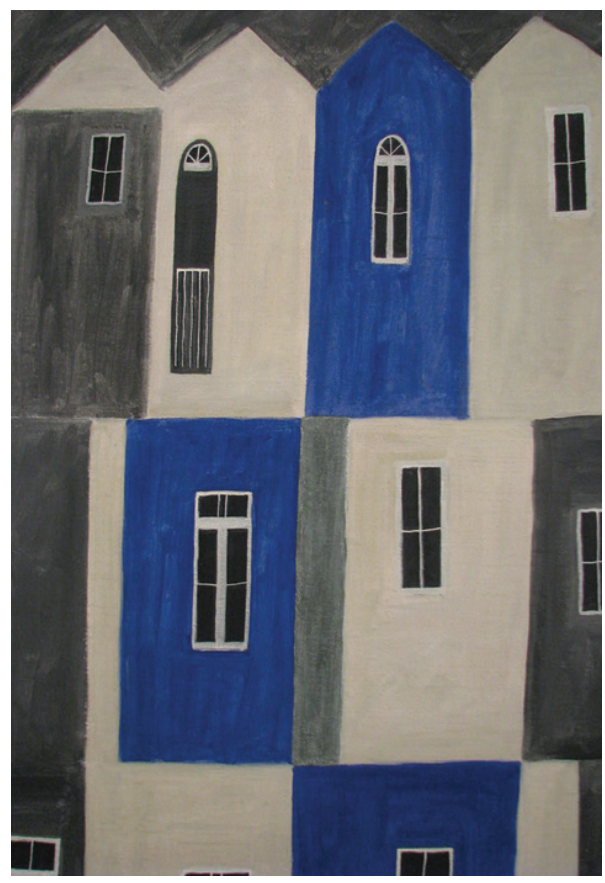

Figura 9: Alfredo Volpi, Casas, 1955. Fonte: https://acervo.mac.usp.br/acervo/media/ collectiveaccess/images/3/3/8495_ca_object representations_media_3353_medium.jpg 


\section{Considerações Finais}

Ao término dos trabalhos, os alunos puderam compreender a importância em elaborar projetos a partir de estudos prévios, que incluíram visitações a museus, pesquisas monitoradas na Internet, leitura de textos e pesquisa visual, além da necessidade de se dominar tecnologias que os capacitassem a simular suas obras antes de construí-las, permitindo prever os problemas e fazer ajustes estéticos e métricos.

Portanto, os alunos, com o devido acompanhamento dos professores, foram protagonistas de suas criações, além de utilizar a linguagem geométrica como uma forma de expressar suas ideias de forma clara, sem perder o apelo estético, artístico e poético.

\section{Bibliografia e Recursos}

Amaral, A. (org.). (1977). Projeto construtivo brasileiro na arte: 1950-1962. Rio de Janeiro: Museu de Arte Moderna; São Paulo: Pinacoteca do Estado.

Cintra, R., Nascimento, A. P. (2002). Grupo Ruptura. São Paulo: Cosac \& Naify, Centro Universitário Maria Antônia da USP.

Mammi, L. Concreta'56: a raiz da forma. Catálogo. São Paulo: MAM, 2006.

Pitta, F., Hannud, G., Ribeiro, J. A., Nery, P., Barros, R. T., Palhares, T., Piccoli, V. (2014). Arte construtiva na Pinacoteca. São Paulo: Pinacoteca do Estado.

Scharf, A. (2000). "Construtivismo", In: STANGOS, Nikos (org). Conceitos da arte moderna. (Á. Cabral, Trad.). Rio de Janeiro: Jorge Zahar Editor.

Arte Concreta (2020, janeiro 10). Recuperado de http:// enciclopedia.itaucultural. org.br/termo3777/arte-concreta.

FreeCAD (2020, janeiro 10). Recuperado de http://www. freecadweb.org/.

Parâmetros Curriculares Nacionais - Matemática (Ensino Médio) (2020, janeiro 10). Recuperado de http://portal. mec.gov.br/seb/arquivos/pdf/ciencian.pdf. 